
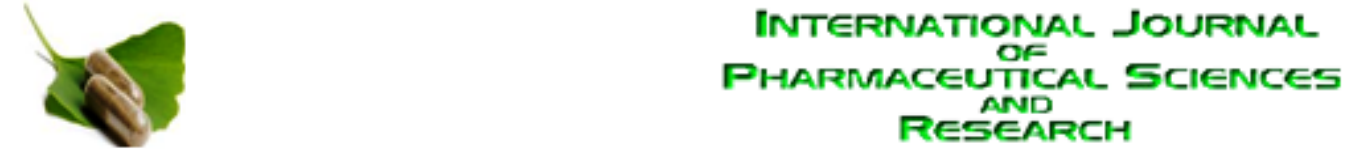

Received on 16 September, 2011; received in revised form 14 November, 2011; accepted 27 December, 2011

\title{
DEVELOPMENT AND IN-VITRO CHARACTERIZATION OF EFFERVESCENT FLOATING DRUG DELIVERY SYSTEM OF FAMOTIDINE
}

Rakesh Pahwa ${ }^{1 *}$, Sumit Jindal ${ }^{1}$, Lovely Chhabra ${ }^{1}$, Himanshu Dutt ${ }^{1}$ and Rekha Rao ${ }^{2}$

Institute of Pharmaceutical Sciences, Kurukshetra University ${ }^{1}$, Kurukshetra-136119, Haryana, India Faculty of Pharmacy, Maharishi Markandeshwar University ${ }^{2}$, Mullana-133203, India

\section{ABSTRACT}

Keywords:

Famotidine,

Floating tablets, HPMC,

In vitro buoyancy,

Controlled release

Correspondence to Author:

Rakesh Pahwa

Assistant Professor, Institute of Pharmaceutical Sciences, Kurukshetra University, Kurukshetra-136119, Haryana, India
The objective of the present study was to prepare and evaluate gastroretentive floating drug delivery system containing famotidine as a model drug. Famotidine tablets were prepared by wet granulation method using two different grades of hydroxypropylmethyl cellulose- HPMC K4M and HPMC K100M by effervescent technique. Sodium bicarbonate (SB) and citric acid (CA) were incorporated as gas-generating agents. Floating tablets were evaluated for uniformity of weight, thickness, hardness, friability, drug content, in vitro buoyancy and dissolution studies. The effect of effervescent agent on drug release profile and floating properties was also investigated. Prepared tablets exhibited controlled and prolonged drug release profiles while floating over the dissolution medium. Non-Fickian diffusion was confirmed as the drug release mechanism from these tablets, indicating that water diffusion and polymer rearrangement played an essential role in drug release. All the prepared tablets showed good in vitro buoyancy.
INTRODUCTION: Oral controlled release dosage forms have been developed for the past three decades due to their considerable therapeutic advantages and applications. The high level of patient compliance in taking oral dosage forms is due to the ease of administration and handling of these forms ${ }^{1}$.

However, the development process is precluded by several physiological difficulties, such as an inability to confine the dosage form within desired region of the gastrointestinal tract, fluctuation in the gastric emptying process etc. This variability may lead to an unpredictable bioavailability of an orally administered dosage form ${ }^{2}$. To increase the gastric retention time of drugs, gastroretentive floating dosage forms are developed which can remain in the gastric region for several hours ${ }^{3}$. Incorporation of the drug in these dosage forms prolong the retention time within the gastrointestinal tract (GIT) until all the drug is completely released at the desired period of time ${ }^{4}$. From the formulation and technological point of view, floating drug delivery system is considerably easy and logical approach in the development of gastroretentive dosage forms ${ }^{5}$.

Gastroretentive floating drug delivery technology is one of the promising approach for enhancing the bioavailability and controlled delivery of drugs that exhibit narrow absorption window ${ }^{6}$. These drug delivery systems have been shown to possess better efficacy in controlling the release rate for drugs with site specific absorption ${ }^{7}$.

Famotidine is a histamine $\mathrm{H}_{2}$ receptor antagonist which is widely prescribed in gastric ulcers, duodenal ulcers, Zollinger-Ellison syndrome and gastroesophageal reflux disease. This drug completely antagonises the parietal 
cell $\mathrm{H}_{2}$ receptor. It inhibits histamine, gastrin and acetylcholine stimulated acid secretion; pepsin secretion also falls with the reduction in volume of gastric juice. It increases the incidence and rate of healing of peptic ulcers ${ }^{8,9}$.

In the present investigation, HPMC K4M and HPMC $\mathrm{K} 100 \mathrm{M}$ were utilized along with gas generating agents such as sodium bicarbonate and citric acid for the formulation of floating tablets of famotidine which would increase the bioavailability, thereby improving the therapeutic efficacy and patient compliance.

MATERIALS AND METHODS: Famotidine was obtained from Oyster Labs Ltd., Ambala, India. HPMC K4M and HPMC K100M were procured from Colorcon Pvt. Ltd, Goa, India. Sodium bicarbonate and Citric acid were received as gift samples from S.D. Fine-Chem
Ltd., Mumbai, India. Polyvinyl pyrrolidone K-30 (PVP K30), Magnesium stearate and Talc were obtained from HiMedia Laboratories Pvt. Ltd., Mumbai, India. Isopropyl alcohol was kindly provided by Qualigens Fine Chemicals, Mumbai, India.

Preparation of Floating Tablets: Tablets were prepared by wet granulation method. First of all, the ingredients were weighed and then mixed thoroughly. Granulation was done with a solution of PVP K-30 in sufficient isopropyl alcohol. After drying in conventional hot air oven at $45^{\circ} \mathrm{C}$, the dried granules were passed through $18 / 22$ mesh, then lubricated with magnesium stearate $(1 \% \mathrm{w} / \mathrm{v})$ and purified talc $(2 \% \mathrm{w} / \mathrm{v})$. Finally, the blend was compressed on a minirotary punching machine with punches of $7 \mathrm{~mm}^{10}$. The composition of different formulations of floating tablets is shown in table 1.

TABLE 1: FORMULATION OF FLOATING TABLETS USING DIFFERENT RATIO OF POLYMER AND EFFERVESCENT AGENTS

\begin{tabular}{|c|c|c|c|c|c|c|c|c|c|c|}
\hline Ingredients (mg) & $\mathbf{F 1}$ & F2 & F3 & F4 & F5 & F6 & F7 & F8 & F9 & F10 \\
\hline Famotidine & 40 & 40 & 40 & 40 & 40 & 40 & 40 & 40 & 40 & 40 \\
\hline HPMC K4M & 40 & 50 & 60 & 60 & 60 & - & - & - & - & - \\
\hline HPMC K100M & - & - & - & - & - & 40 & 50 & 60 & 60 & 60 \\
\hline Sodium Bicarbonate & 20 & 20 & 20 & 20 & 20 & 20 & 20 & 20 & 20 & 20 \\
\hline Citric Acid & 2 & 2 & 2 & 3 & 4 & 2 & 2 & 2 & 3 & 4 \\
\hline PVP K-30 & 20 & 20 & 20 & 20 & 20 & 20 & 20 & 20 & 20 & 20 \\
\hline Magnesium Stearate & 2 & 2 & 2 & 2 & 2 & 2 & 2 & 2 & 2 & 2 \\
\hline Talc & 4 & 4 & 4 & 4 & 4 & 4 & 4 & 4 & 4 & 4 \\
\hline
\end{tabular}

Evaluation of Granules: Prior to compression, granules were evaluated for their characteristic parameters, such as Bulk density, tapped density, Carr's index, Hausner's ratio and angle of repose. The angle of repose was determined by the fixed funnel method. Bulk density, tapped density, Carr's index and Hausner's ratio were calculated using tap density apparatus (Electrolab, USP) ${ }^{11}$.

Evaluation of Tablets: The prepared tablets were evaluated for uniformity of weight using 20 tablets. Hardness, thickness and friability were measured with Pfizer hardness tester, vernier calliper and Roche friabilator respectively. The results were expressed as mean \pm Standard deviation ${ }^{12-14}$.

Drug Content Uniformity: Twenty tablets were taken and powdered; powder equivalent to one tablet was accurately weighed and was allowed to dissolve in 100 $\mathrm{mL}$ of $0.1 \mathrm{~N} \mathrm{HCl}$, followed by stirring for 30 minutes. The solution was filtered through $0.45 \mu \mathrm{m}$ membrane filter, diluted suitably and analysed using UV/Visible spectrophotometer at $265 \mathrm{~nm}$ using $0.1 \mathrm{~N} \mathrm{HCl}$ as blank 12

In vitro Buoyancy Studies: The in vitro buoyancy was determined by floating lag time. The tablets were placed in a $100 \mathrm{~mL}$ beaker containing $0.1 \mathrm{~N} \mathrm{HCl}$. The time required for the tablet to rise to the surface and float was taken as the floating lag time. The mean \pm S.D. values of buoyancy were calculated ${ }^{15}$.

Determination of Swelling Index: The swelling index of tablets was determined in $900 \mathrm{~mL}$ of $0.1 \mathrm{~N} \mathrm{HCl}$ at $37 \pm 0.5^{\circ} \mathrm{C}$. The swollen weight of the tablet was determined at predefined time intervals. The swelling index was calculated by the following equation:

$$
\text { Swelling index }=\left(w_{2}-w_{1}\right) / w_{1} \times 100
$$

Where, $w_{1}=$ initial weight of tablet; $w_{2}=$ final weight after swelling of tablet. 
The mean \pm standard deviation values of swelling index were calculated $^{16}$.

In vitro Dissolution Studies: In vitro dissolution studies were carried out using USP dissolution apparatus type II at $50 \mathrm{rpm}$. The dissolution medium consisted of 900 $\mathrm{mL}$ of $0.1 \mathrm{~N} \mathrm{HCl}$, maintained at $37 \pm 0.5^{\circ} \mathrm{C} .10 \mathrm{~mL}$ of the sample was withdrawn at suitable time intervals and immediately replaced with an equal volume of $0.1 \mathrm{~N}$ $\mathrm{HCl}$ to maintain the volume constant. The samples were filtered through a $0.45 \mu \mathrm{m}$ membrane filter, diluted sufficiently and analysed at $265 \mathrm{~nm}$ using UV/Visible double-beam spectrophotometer ${ }^{17}$.

Kinetic Modelling of Drug Release: The suitability of several equations, which are reported in the literature to identify the mechanism(s) for the release of drug, was tested with respect to the release data ${ }^{18-21}$. Data were evaluated according to the following equations mentioned in table 2:

\section{TABLE 2: KINETIC MODEL EQUATIONS}

\begin{tabular}{cc}
\hline Model & Equation \\
\hline Zero order & $\mathrm{F}=\mathrm{K}_{0} \mathrm{t}$ \\
First order & $\ln \mathrm{F}=\mathrm{K}_{1} \mathrm{t}$ \\
Higuchi & $\mathrm{F}=\mathrm{K}_{\mathrm{H}} \mathrm{t}^{0.5}$ \\
Korsmeyer and Peppas model & $\mathrm{F}=\mathrm{Kt}^{\mathrm{n}}$ \\
\hline
\end{tabular}

Where $F$ is the fraction of drug release constant, $t$ is the time, $n$ diffusion coefficient

\section{RESULTS AND DISCUSSION:}

Characterization of Granules: Granules prepared for compression of floating tablets were evaluated for their flow properties like angle of repose, bulk density, tapped density, compressibility index and Hausner's ratio. The results are shown in table 3. Bulk density was found between $0.370-0.391 \mathrm{gm} / \mathrm{cm}^{3}$ with HPMC $\mathrm{K} 4 \mathrm{M}$ and 0.365-0.395 $\mathrm{gm} / \mathrm{cm}^{3}$ with HPMC K100M. Tapped density ranged between $0.438-0.460 \mathrm{gm} / \mathrm{cm}^{3}$ with granules containing HPMC K4M, 0.427-0.452 $\mathrm{gm} / \mathrm{cm}^{3}$ with HPMC K100M. Carr's index was found to be in the range of 11.33-15.52 for both formulations, indicating good flow.

Flowability of granules was found to be good as indicated by compressibility-flowability correlation data. Hausner's ratio is related to interparticle friction. Hausner's ratio values for all formulations were found to be near about 1.2 indicating low interparticle friction. Angle of repose was found to be in the range of $24.34^{\circ}-29.40^{\circ}$ with HPMC K4M and $23.70^{\circ}-25.40^{\circ}$ with HPMC K100M. The values of angle of repose were less than 30 , indicating good flowability.

TABLE 3: CHARACTERIZATION OF GRANULES

\begin{tabular}{cccccc}
\hline S. No. & Bulk Density $\left(\mathbf{g m} / \mathbf{c m}^{\mathbf{3}}\right)$ & Tapped Density $\left(\mathbf{g m} / \mathbf{c m}^{\mathbf{3}}\right)$ & Carr's Index $(\%)$ & Hausner's Ratio $\left(\mathbf{H}_{\mathbf{R}}\right)$ & Angle of repose $(\boldsymbol{\theta})$ \\
\hline F1 & 0.390 & 0.455 & 14.28 & 1.167 & 24.34 \\
F2 & 0.390 & 0.460 & 15.21 & 1.179 & 26.30 \\
F3 & 0.370 & 0.438 & 15.52 & 1.153 & 27.69 \\
F4 & 0.385 & 0.445 & 13.48 & 1.127 & 29.40 \\
F5 & 0.391 & 0.441 & 11.33 & 1.173 & 28.80 \\
F6 & 0.374 & 0.439 & 14.80 & 1.139 & 24.70 \\
F7 & 0.393 & 0.448 & 12.27 & 1.169 & 24.69 \\
F8 & 0.365 & 0.427 & 14.51 & 1.144 & 25.40 \\
F9 & 0.395 & 0.452 & 12.61 & 1.131 & 23.96 \\
F10 & 0.389 & 0.440 & 11.59 & & \\
\hline
\end{tabular}

Physicochemical Evaluation: Floating tablets of famotidine were prepared by effervescent technique using HPMC (K4M, K100M), sodium bicarbonate, citric acid and PVP K-30. The magnesium stearate and talc were used as lubricant and glidant, respectively. Findings of the physicochemical characterization are shown in table 4. Average weight of floating tablets in all the formulations varied between $198.15 \mathrm{mg}$ to $199.15 \mathrm{mg}$. Variation was determined less than $7.5 \%$ which is found to be within limits as prescribed in USP. Thickness of tablets of all the formulations was observed in between $3.28 \mathrm{~mm}$ to $3.38 \mathrm{~mm}$ which is found to be satisfactory. The hardness for different formulations was found to be between 5.13 to $5.93 \mathrm{~kg} / \mathrm{cm}^{2}$ indicating satisfactory mechanical strength. The friability was below $1 \%$ for all formulations, which is an indication of good mechanical resistance of the tablets. Drug content varied in between $97.40 \%$ to $98.29 \%$ for different formulations, indicating good content uniformity. 
TABLE 4: VARIOUS PHYSICOCHEMICAL CHARACTERISTICS OF FLOATING TABLETS

\begin{tabular}{|c|c|c|c|c|c|c|c|c|c|c|}
\hline $\begin{array}{c}\text { Evaluation } \\
\text { Parameters }\end{array}$ & F1 & F2 & F3 & F4 & F5 & F6 & F7 & F8 & F9 & F10 \\
\hline $\begin{array}{c}\text { Average weight } \\
(\mathrm{mg}) \pm \text { S.D. }\end{array}$ & $198.80 \pm 0.76$ & $198.15 \pm 0.98$ & $198.35 \pm 0.93$ & $198.55 \pm 1.53$ & $198.30 \pm 1.75$ & $198.50 \pm 1.60$ & $199.15 \pm 1.69$ & $198.75 \pm 1.71$ & $199.05 \pm 1.60$ & $198.40 \pm 1.66$ \\
\hline Thickness (mm) & $3.34 \pm 0.054$ & $3.38 \pm 0.083$ & $3.34 \pm 0.054$ & $3.34 \pm 0.054$ & $3.32 \pm 0.083$ & $3.30 \pm 0.070$ & $3.28 \pm 0.083$ & $3.34 \pm 0.114$ & $3.28 \pm 0.083$ & $3.28 \pm 0.083$ \\
\hline $\begin{array}{l}\text { Hardness } \\
\left(\mathrm{kg} / \mathrm{cm}^{2}\right)\end{array}$ & $5.76 \pm 0.30$ & $5.93 \pm 0.25$ & $5.70 \pm 0.10$ & $5.50 \pm 0.10$ & $5.83 \pm 0.15$ & $5.13 \pm 0.15$ & $5.50 \pm 0.10$ & $5.46 \pm 0.15$ & $5.36 \pm 0.15$ & $5.46 \pm 0.15$ \\
\hline Friability (\%) & 0.43 & 0.47 & 0.31 & 0.45 & 0.56 & 0.57 & 0.43 & 0.48 & 0.35 & 0.39 \\
\hline $\begin{array}{c}\text { Drug Content } \\
(\%) \\
\end{array}$ & 97.40 & 98.08 & 98.08 & 97.75 & 97.95 & 97.95 & 98.20 & 98.16 & 98.29 & 98.25 \\
\hline $\begin{array}{c}\text { Swelling Index } \\
(\%)\end{array}$ & $70.00 \pm 1.00$ & $95.30 \pm 2.51$ & $144.60 \pm 1.52$ & $150.00 \pm 2.00$ & $165.00 \pm 5.00$ & $155.00 \pm 5.00$ & $205.10 \pm 5.00$ & $220.10 \pm 5.25$ & $235.00 \pm 2.50$ & $254.10 \pm 3.68$ \\
\hline $\begin{array}{l}\text { Floating lag } \\
\text { time (sec.) }\end{array}$ & $18.33 \pm 1.52$ & $22.00 \pm 1.00$ & $39.66 \pm 1.52$ & $35.66 \pm 1.52$ & $29.33 \pm 1.52$ & $40.00 \pm 1.52$ & $43.66 \pm 2.00$ & $48.33 \pm 1.52$ & $39.00 \pm 2.00$ & $33.66 \pm 1.52$ \\
\hline $\begin{array}{c}\text { Total floating } \\
\text { time (hr.) }\end{array}$ & $>12 \mathrm{hr}$ & $>12 \mathrm{hr}$ & $>12 \mathrm{hr}$ & $>12 \mathrm{hr}$ & $>12 \mathrm{hr}$ & $>12 \mathrm{hr}$ & $>12 \mathrm{hr}$ & $>12 \mathrm{hr}$ & $>12 \mathrm{hr}$ & $>12 \mathrm{hr}$ \\
\hline
\end{tabular}

In vitro Buoyancy Studies: The combination of SB and $\mathrm{CA}$ is required for good floating ability and therefore, this combination was selected for the formulation of floating tablets. Buoyancy of the tablets is governed by both the swelling of hydrocolloid particles on the tablet surface and the presence of internal voids in the dry centre of tablet (porosity). These two factors are essential for the tablet to acquire bulk density less than 1 and so remain buoyant on gastric fluid.

Results of floating lag time and total floating time are shown in table 4. All the formulations constantly floated on dissolution medium for more than $12 \mathrm{hrs}$. All the batches were found to exhibit short floating lag times due to presence of SB and CA. Decrease in CA level increased the floating lag time and tablets were found to float for longer duration. The tablets with low-viscosity grade HPMC K4M exhibited short floating lag time as compared with formulations containing high viscosity grade HPMC K100M. Thus, a combination of SB and CA with HPMC was found to achieve in vitro buoyancy and floatability.

Swelling Indices: HPMC is a hydrophilic polymer. It swells on contact with water. The hydration ability of the formula is significant because it influences: (a) tablet buoyancy, (b) adhesion ability of swellable polymers as HPMC K4M and HPMC K100M, (c) drug release kinetics. The thickness of swollen layer formed around the matrix core was greater in matrices containing HPMC of higher viscosity grade. Thus, swelling index was comparatively less in tablets containing HPMC K4M than that of tablets containing HPMC K100M.
With the increase in citric acid concentration in formulations containing HPMC K4M and HPMC K100M, it was found that swelling of polymer increases due to higher gas pressure caused by faster and higher carbon dioxide generation.

It was evident from the results that as the citric acid concentration was increased in formulations i.e. F3-F5 containing HPMC K4M and F8-F10 of HPMC K100M, swelling index was also increased from 144.60\%$165.00 \%$ and $220.10 \%-254.10 \%$ respectively. Results of swelling index are shown in table 4 . Fig. 1 and $\mathbf{2}$ depict graphical representations that were plotted with \% swelling index versus time (hrs).

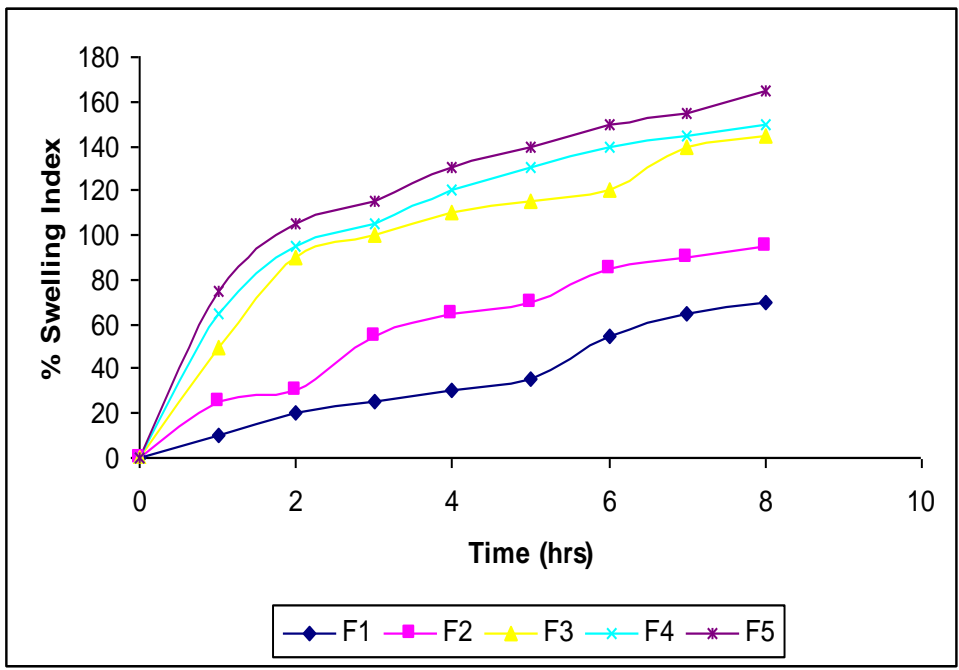

FIG. 1: SWELLING INDICES OF FORMULATION F1-F5 CONTAINING FAMOTIDINE 


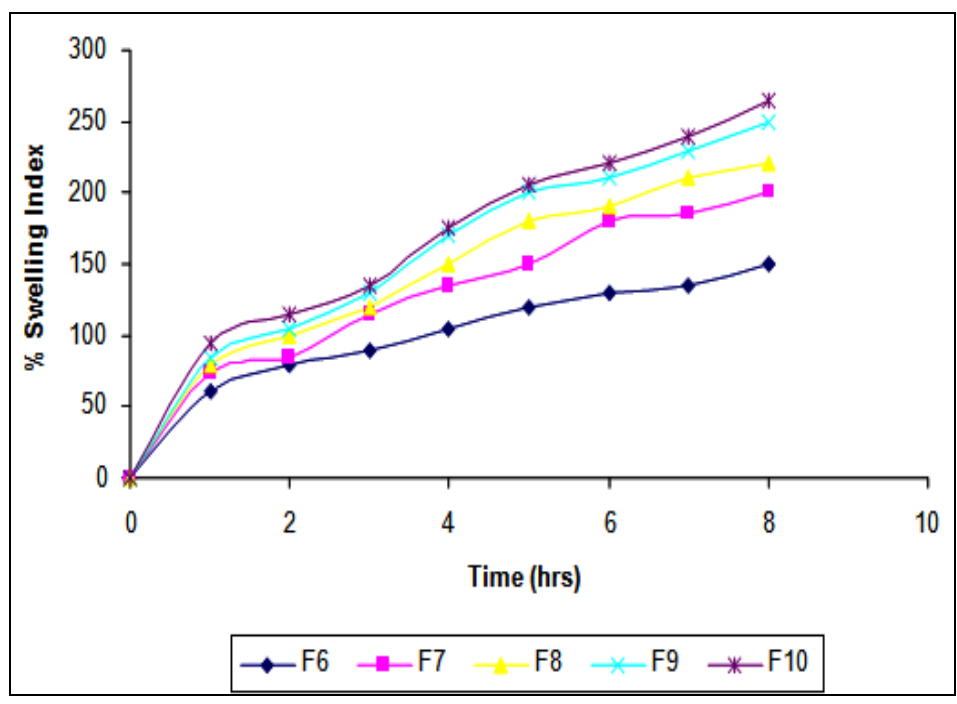

FIG. 2: SWELLING INDICES OF FORMULATION F6-F10 CONTAINING FAMOTIDINE

In vitro Dissolution Studies: On increasing the proportion of HPMC in formulations, the release of drug was observed to be decreased. This might be due to increase in resistance of the gel layer to drug dissolution. At a high polymer level, formation of tightly swollen gel layer caused by more intimate contact between the particles of HPMC results in decrease mobility of drug particles in swollen matrices, which leads to decreased release rate. It is evident from in-vitro dissolution data that increase in citric acid concentration increased the release rate but reduced the floating time, probably due to the presence of excess carbon dioxide. Comparing different grades of HPMC, it was found that HPMC K100M provided better release characteristics with floating time of $10 \mathrm{hrs}$. The cumulative $\%$ drug release $\mathrm{v} / \mathrm{s}$ time plots for different formulations are presented in fig. 3 and $\mathbf{4}$.

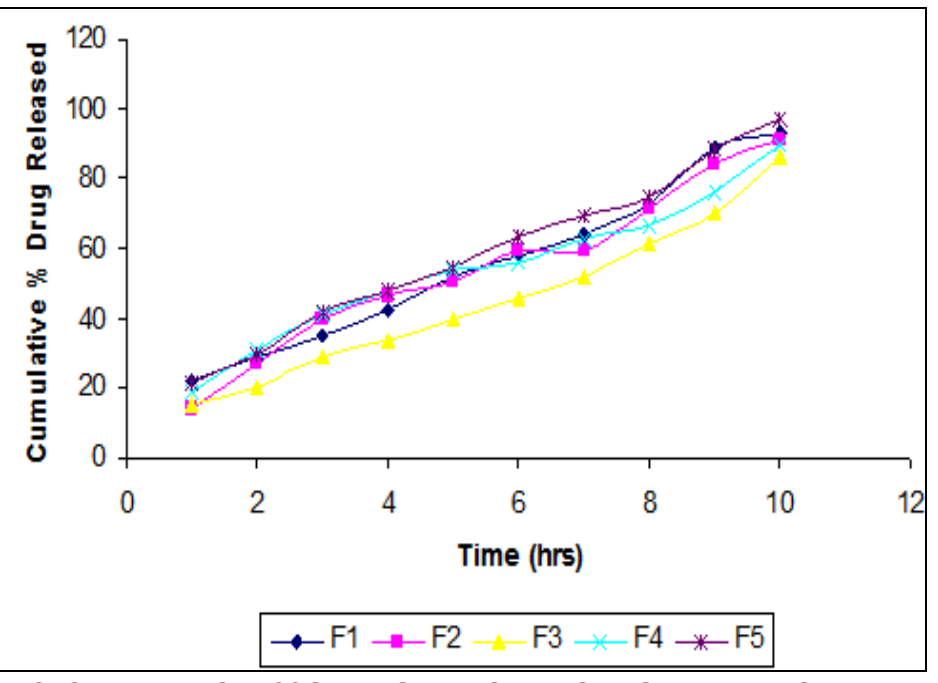

FIG. 3: IN VITRO DISSOLUTION PROFILE OF FORMULATION F1-F5

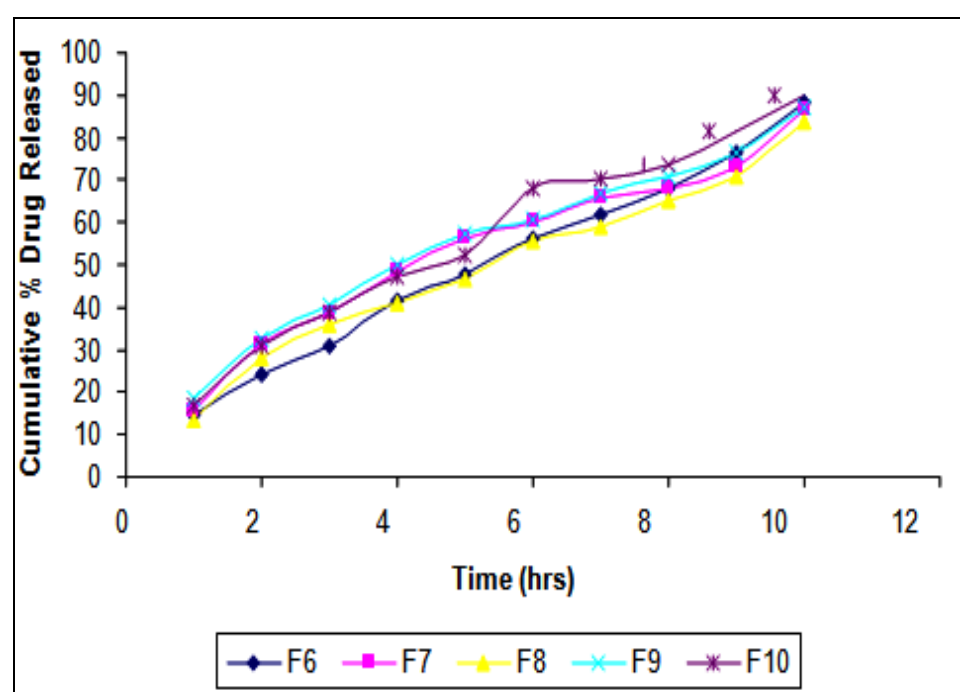

FIG. 4: IN VITRO DISSOLUTION PROFILE OF FORMULATION F6F10

Mathematical Modelling of Drug Release: Data obtained from in vitro dissolution studies were fitted in different models viz. Zero order, First order, Korsemeyer-Peppas and Higuchi model. The data were processed for regression analysis using MS EXCEL statistical function. The release constant was calculated from the slope of the appropriate plots, and the regression coefficient $\left(r^{2}\right)$ was determined as shown in table 5.

To confirm the exact mechanism of drug release from these tablets, the data were fitted to Korsemeyer and Peppas model. The ' $n$ ' value of Korsemeyer- Peppas model for the different formulations was found between 0.615 and 0.764 which lies within the range of 0.5 and 1.0. Therefore, the most probable mechanism that the release pattern of all formulations followed was non-fickian diffusion or anomalous diffusion, where in the drug release mechanism is controlled by both diffusion as well as polymer relaxation process.

CONCLUSION: From the above studies, it has been observed that effervescent based floating drug delivery system is a promising approach to achieve controlled release behaviour and in vitro buoyancy profile. Floating tablets employing famotidine as a model drug can be prepared successfully using wet granulation technique. It was concluded that all formulations had acceptable physical parameters. The addition of gelforming polymer HPMC (K4M and K100M) and gasgenerating agents were essential to achieve in vitro buoyancy. 
TABLE 5: FIT OF VARIOUS KINETIC MODELS FOR FLOATING DRUG DELIVERY SYSTEMS OF FAMOTIDINE

\begin{tabular}{|c|c|c|c|c|c|c|c|c|}
\hline \multirow{2}{*}{$\begin{array}{c}\text { Formulation } \\
\text { Code }\end{array}$} & \multicolumn{2}{|c|}{ Zero order } & \multicolumn{2}{|c|}{ First order } & \multicolumn{2}{|c|}{ Higuchi model } & \multicolumn{2}{|c|}{ Peppas model } \\
\hline & $r^{2}$ & $\mathrm{~K}_{0}$ & $r^{2}$ & $K_{1}\left(h^{-1}\right)$ & $r^{2}$ & $K_{H}\left(h^{-1 / 2}\right)$ & $r^{2}$ & $\mathbf{n}$ \\
\hline F1 & 0.9873 & 7.968 & 0.8500 & 2.445 & 0.9466 & 33.34 & 0.9631 & 0.638 \\
\hline F2 & 0.9769 & 7.831 & 0.7850 & 0.213 & 0.9710 & 33.37 & 0.9468 & 0.762 \\
\hline F3 & 0.9733 & 7.328 & 0.8990 & 0.167 & 0.9214 & 30.47 & 0.9800 & 0.722 \\
\hline F4 & 0.9727 & 6.835 & 0.8479 & 0.182 & 0.9665 & 29.12 & 0.9869 & 0.615 \\
\hline F5 & 0.9935 & 8.039 & 0.7989 & 0.286 & 0.9746 & 34.03 & 0.9880 & 0.648 \\
\hline F6 & 0.9954 & 7.746 & 0.9060 & 0.188 & 0.9790 & 32.91 & 0.9960 & 0.764 \\
\hline F7 & 0.9612 & 6.872 & 0.8893 & 0.169 & 0.9841 & 29.72 & 0.9858 & 0.733 \\
\hline F8 & 0.9811 & 6.897 & 0.9401 & 0.153 & 0.9795 & 29.45 & 0.9771 & 0.671 \\
\hline F9 & 0.9735 & 6.861 & 0.9386 & 0.174 & 0.9819 & 29.60 & 0.9910 & 0.633 \\
\hline F10 & 0.9786 & 7.691 & 0.9372 & 0.210 & 0.9880 & 33.03 & 0.9915 & 0.707 \\
\hline
\end{tabular}

The type of polymer also affects the drug release rate. Polymer swelling is crucial in determining the drug release rate and is also important for floatation. Based on these findings, it has been revealed that floating type gastroretentive drug delivery system holds significant potential for better drug delivery and facilitates an enormous impact on health care. Moreover, it is anticipated that increased sophistication of this effervescent approach will ensure the successful delivery of therapeutic molecules in a more efficient manner.

ACKNOWLEDGEMENT: The authors would like to express their sincere gratitude to Professor Om Prakash, Dean and Director, Institute of Pharmaceutical Sciences, Kurukshetra University, Kurukshetra-136119, India for providing necessary facilities to carry out this work.

\section{REFERENCES:}

1. Wilson CG, Washington N. Physiological Pharmaceutics: Biological Barriers to Drug Absorption. Horwood Ellis, Chichester, 1989; 47-70.

2. Singh BN, Kim KH. Floating drug delivery systems: An approach to oral controlled drug delivery via gastric retention. Journal of Controlled Release 2000; 63: 235-259.

3. Garg R, Gupta GD. Progress in controlled gastroretentive delivery systems. Tropical Journal of Pharmaceutical Research 2008; 7(3): 10551066.

4. Prajapati ST, Patel LD, Patel DM. Gastric floating matrix tablets: Design and optimization using combination of polymers. Acta Pharmaceutica 2008; 58: 221-229.

5. Pahwa R, Bhagwan S, Kumar V, Kohli K. Role of natural polymers in the development of floating drug delivery systems. Journal of Pharmacy Research 2010; 3(6): 1312-1318.
6. Pahwa R, Neeta, Bhagwan S, Kumar V, Kohli K. Floating microspheres: An innovative approach for gastric retention. Der Pharmacia Lettre 2010; 2(4): 461-475.

7. Kumar R, Philip A. Gastroretentive dosage forms for prolonging gastric residence time. International Journal of Pharmaceutical Medicine 2007; 21(2): 157-171.

8. Rang HP, Dale MM, Ritter JM, Moore PK. Pharmacology. Churchill livingstone, Fifth Edition 2003; 370.

9. Tripathi KD. Essential of Medical Pharmacology, Jaypee Brothers, Fifth Edition 2003; 589-591.

10. Jaimini $M$, Rana AC, Tanwar YS. Formulation and evaluation of famotidine floating tablets. Current Drug Delivery 2007; 4: 51-55.

11. Sonar GS, Jain DK, More DM. Preparation and in vitro evaluation of bilayer and floating bioadhesive tablets of rosiglitazone maleate. Asian Journal of Pharmaceutical Sciences 2007; 2(4): 161-169.

12. Castellanos MRJ, Zia $\mathrm{H}$, Rhodes $\mathrm{CT}$. Design and testing in vitro of a bioadhesive and floating drug delivery system for oral application. International Journal of Pharmaceutics 1994; 105: 65-70.

13. Rao BP, Kottan NA, Snehith VS, Ramesh C. Development of gastroretentive drug delivery system of cephalexin by factorial design. ARS Pharmaceutica 2009; 50(1): 8-24.

14. Kar M, Reddy MS. Design and evaluation of floating drug delivery system for an antipsychotic agent: A technical report. PDA Journal of Pharmaceutical Science and Technology 2006; 60(6): 389-394.

15. Baumgartner S, Tivador A, Vrecer F, Kristil JO. Development of floating tablets as a new approach to the treatment of Helicobacter pylori infections. Acta Pharmaceutica 2001; 51: 21-33.

16. Chaudhari P, Chaudhari S, Barhate N, Mistry C, Kolsure P. Design and evaluation of bilayer floating tablets of tizanidine hydrochloride. Indian Journal of Pharmaceutical Education and Research 2008; 42(1): 36-47.

17. Dave BS, Amin AF, Patel MM. Gastro retentive drug delivery system of ranitidine hydrochloride: Formulation and in vitro evaluation. AAPS Pharm. Sci. Tech 2004; 5(2): Article 34.

18. Chen $\mathrm{GL}, \mathrm{Hao} \mathrm{WH}$. In vitro performance of floating sustained release capsules of verapamil. Drug Development and Industrial Pharmacy 1998; 24: 1067-1072.

19. Shah MV, De Gennaro MD, Suryakarma H. An evaluaton of albumin microcapsules prepared using a multiple emulsion technique. Journal of Microcapsulation 1987; 4: 223-238.

20. Higuchi T. Rate of release of medicaments from ointment bases containing drugs in suspension. Journal of Pharmaceutical Sciences 1961; 50: 874-875.

21. Korsmeyer RW, Deolkar GEP, Peppas NA. Mechanisms of potassium chloride from compressed, hydrophilic, polymeric matrices: Effect of entrapped air. Journal of Pharmaceutical Sciences 1983; 72: 1189-1191. 